\title{
Effects of oral fat perception by modified sham feeding on energy expenditure, hormones and appetite profile in the postprandial state
}

\author{
Astrid J. Smeets $^{1,2}$, Manuela P. Lejeune ${ }^{1,2}$ and Margriet S. Westerterp-Plantenga ${ }^{1,2}$ \\ ${ }^{1}$ Department of Human Biology, Maastricht University, PO Box 616, 6200 MD Maastricht, The Netherlands \\ ${ }^{2}$ Top Institute Food and Nutrition, PO Box 557, 6700 AN Wageningen, The Netherlands
}

(Received 13 December 2007 - Revised 14 July 2008 - Accepted 31 July 2008 - First published online 25 September 2008)

Previously, we have shown that satiety and metabolites increased after high-fat modified sham feeding (MSF). We assessed possible metabolic effects due to oral stimulation with a high-fat sham-fed 'meal', in comparison with a high-fat fed meal and with water, in the postprandial state. Fourteen healthy women (aged $18-40$ years; BMI 22.5 (SD 3) $\mathrm{kg} / \mathrm{m}^{2}$ ) were fed in energy balance during $4 \mathrm{~d}$ with a $50 \%$ enegy as carbohydrate, $15 \%$ energy as protein and $35 \%$ energy as fat menu. On day 4 , subjects were given one out of three test lunches, $5 \mathrm{~h}$ after a high-fat breakfast, in random order: a high-fat MSF lunch, water (W) or the same lunch to be eaten (E), during their $36 \mathrm{~h}$ stay in the respiration chamber, where substrate oxidation, $24 \mathrm{~h}$ energy expenditure (EE) and appetite profile were measured. Oral fat stimulation by MSF increased EE (W $6.3(\mathrm{SD} \mathrm{0.8)} v$. MSF $6.9(\mathrm{SD} 1.0) \mathrm{kJ} / \mathrm{min}$ and E $6.8(\mathrm{SD} 0.7) \mathrm{kJ} / \mathrm{min} ; P<0.04)$ for $1 \mathrm{~h}$, increased plasma insulin concentrations $(\mathrm{t}=15$; W 10.0 (SD 3.4) v. MSF 13.2 (SD 4.0) v. E 22.3 (SD 3.3) units $/ 1 ; P<0.0001$ ), attenuated changes in plasma NEFA concentrations $(\mathrm{t}=15$, W 432 (SD 108) v. MSF 418 (SD 146) v. E 282 (SD 72) $\mu$ mol/l; $P<0.0001$ ), plasma TAG concentrations $(\mathrm{t}=60 ; \mathrm{W} 1092$ (SD 548) v. MSF 1116 (SD 493) $\mu \mathrm{mol} / 1$ and E 1350 (SD 352) $\mu \mathrm{mol} / 1 ; P<0 \cdot 02$ ) and plasma glycerol concentrations $(\mathrm{t}=15$, W 87 (SD 29$) v$. MSF 74 (SD 34 ) $\mu \mathrm{mol} / \mathrm{l}$ and $\mathrm{E} 67$ (SD 18) $\mu \mathrm{mol} / \mathrm{l} ; P<0.03$ ). Over a longer period of time, MSF had no effects on substrate oxidation, diet-induced thermogenesis or total EE. In addition to the previously observed metabolic effects of oral stimulation with fat, EE is stimulated up to $1 \mathrm{~h}$ after the MSF meal.

Fat: Modified sham feeding: Satiety: Energy expenditure: Substrate oxidation: ${ }^{2}$ H-labelled palmitic acid

Obesity is associated with an increased risk for hypertension, dyslipidaemia, type 2 diabetes, CHD, stroke and certain cancers $^{(1)}$. The prevalence of obesity is still increasing. To reverse this trend, a sustained and effective treatment strategy is needed. Sustaining satiety, while decreasing the amount of energy ingested, is one of the targets in an effective obesity treatment. Meal size and meal frequency determine total energy intake. Oral sensory signals play a role in determining meals size ${ }^{(2)}$, while metabolic signals such as appearance of metabolites, anorexigenic hormones, diet-induced thermogenesis and substrate oxidation play a role in determining the inter-meal interval $^{(3)}$. However, the question remains whether oral signals have an effect on metabolic satiety, and, if so, the magnitude of this effect.

In a recent study we have observed a short increase in concentrations of metabolites and satiety after oral stimulation with high-fat foods ${ }^{(4)}$. Oral stimulation (with fat) experiments by other researchers using the modified sham feeding (MSF) technique, have shown effects on metabolites, hormones and satiety as well ${ }^{(5-16)}$. Oral stimulation seems to increase the availability of oxidisable metabolites, without receiving any exogenous nutrients. Whether these oxidisable metabolites are oxidised is not clear. Stable-isotope techniques are useful tools to investigate the origin of the oxidisable metabolites. In the present study we have used ${ }^{2} \mathrm{H}$-labelled palmitic acid, added to a high-fat breakfast, to investigate the effect of sensory stimulation with fat on substrate utilisation.

Until now few studies have examined the effects of oral stimulation on thermogenesis ${ }^{(10,17-20)}$. In addition to energy expenditure measurements, plasma glucose and insulin concentrations, and the appetite profile were determined in most studies. In the present study we investigated the possible effects of sensory satiety on metabolic satiety, i.e. substrate oxidation and energy expenditure, in energy balance, in a highly controlled environment.

\section{Subjects and methods}

Subjects

Sixteen women were initially selected based on age, height, weight, BMI and restrained eating score (F1 score) on the three-factor eating questionnaire (TFEQ) ${ }^{(21)}$; two women dropped out because of personal reasons. Eating behaviour was assessed using a validated Dutch translation of the TFEQ. Cognitive restrained and unrestrained eating behaviour

Abbreviations: ANCOVA, analysis of covariance; DIT, diet-induced thermogenesis; GLP-1, glucagon-like peptide 1; MSF, modified sham feeding; SMR, sleeping metabolic rate; VAS, visual analogue scale.

* Corresponding author: Dr A. J. Smeets, fax + 31 433670976, email astrid.smeets@hb.unimaas.nl 
(factor 1), emotional eating and disinhibition (factor 2) and the subjective feeling of hunger (factor 3 ) were scored. Fourteen females (BMI 23.2 (SD 2.7) $\mathrm{kg} / \mathrm{m}^{2}$; age 24.4 (SD 7.1) years; TFEQ F1, 4 (SD 3); body fat 27.4 (SD 6.9) \%) were studied on three occasions. All subjects were healthy, not taking medication, non-smoking and not dieting. Subjects were excluded from participation if their factor 1 score on the TFEQ was $>9$. All subjects gave written informed consent and the study was approved by the Maastricht University Ethics Committee.

\section{Study protocol}

The study had a randomised cross-over design and three experimental conditions. Subjects underwent three $36 \mathrm{~h}$ sessions in energy balance in a respiration chamber for measurements of energy expenditure and substrate oxidation. The three $36 \mathrm{~h}$ sessions were conducted 4 weeks apart to ensure that each subject was in the same phase of her menstrual cycle. At $3 \mathrm{~d}$ before each $36 \mathrm{~h}$ session, subjects were provided with a diet in energy balance, and with the same macronutrient composition (50\% energy from carbohydrate, $35 \%$ energy from protein, $15 \%$ energy from fat) at home. We gave our subjects a diet $3 \mathrm{~d}$ before the experiment in the respiration chamber at $100 \%$ of their daily energy needs and with the same macronutrient composition as the diet during the experiment. Before the test was started, subjects were asked whether they had encountered any difficulties while consuming the diet at home. Apart from some subjects that were not able to finish their complete dinner on day 1 of the diet, no irregularities were reported. The subjects entered the respiration chamber at 18.00 hours and subsequently received the dinner of day 3 before the $36 \mathrm{~h}$ session. Subjects were instructed to go to bed at about 23.00 hours. After an overnight stay in the respiration chamber the test day started the following morning at 08.00 hours. On each test day subjects consumed breakfast at 08.00 hours, which consisted of two croissants with butter and a cup of chocolate milk ( $40 \%$ energy from carbohydrate, $20 \%$ energy from protein, $40 \%$ energy from fat). At 12.00 hours $(\mathrm{t}=0)$ the subjects were given one of three test lunches in random order: a high-fat lunch, which consisted of a soup and a salad (25\% energy from carbohydrate, $7 \%$ energy from protein, $68 \%$ energy from fat), the same lunch sham fed, or water. Dinner consisted of pasta with a vegetarian tomato sauce, orange juice and yogurt with fruits, and was served at 16.30 hours to make the protocol more convenient for the subjects. The $24 \mathrm{~h}$ energy intake was compensated at dinner to keep the subjects in energy balance over $24 \mathrm{~h}$.

\section{Energy intake}

During each experimental session subjects were fed in energy balance. The energy content of the diet that the subjects consumed at home was based on BMR calculated with the Harris-Benedict equation ${ }^{(22)}$ and multiplied by an activity index of $1.7^{(23)}$. In the respiration chamber energy requirements were calculated based on sleeping metabolic rate (SMR) measured during the first night and multiplied by an activity index of $1 \cdot 5^{(23)}$. Energy intake in the water and MSF lunch condition was divided over the meals as $30 \%$ for breakfast (08.00 hours) and $70 \%$ for dinner (16.30 hours).
In the eaten lunch condition energy intake was divided over the meals as $30 \%$ for breakfast (08.00 hours), $20 \%$ for lunch (12.00 hours) and $50 \%$ for dinner (16.30 hours). The macronutrient composition of each $24 \mathrm{~h}$ diet was $15 \%$ energy from protein, $35 \%$ energy from fat and 50\% energy from carbohydrates.

\section{Modified sham feeding}

In the MSF condition the subjects were presented with the test lunch and were instructed to chew the food until the point at which they would normally swallow and then to expectorate the food into a plastic bowl. They were continually instructed not to swallow any food. The subjects repeated the procedure until the meal had been fed completely $(15-20 \mathrm{~min})$. Wet and freeze-dried weights of each meal after MSF and a duplicate meal (which was not used for MSF) were measured.

\section{Blood collection and analytical methods}

At $1 \mathrm{~h}$ before the lunch, a Teflon catheter was placed in the antecubital vein for blood sampling. Blood samples were collected $60(\mathrm{t}=-1)$ and $5(\mathrm{t}=0)$ min before and $15(\mathrm{t}=1), 30$ $(\mathrm{t}=2), 60(\mathrm{t}=3)$ and $120(\mathrm{t}=4) \mathrm{min}$ after the lunch in tubes containing EDTA to prevent clotting. Plasma was obtained by centrifugation $\left(4^{\circ} \mathrm{C} ; 3000 \mathrm{rpm} ; 10 \mathrm{~min}\right)$ and stored at $-20^{\circ} \mathrm{C}$ until analysis of glucose by a hexokinase method (ABX Diagnostics, Montpellier, France), insulin (RIA kit; Linco Research, Inc., St Charles, MO, USA), NEFA (NEFA C-kit Wako 994-75 409; Sopar Biochemicals, Koekelberg, Belgium), TAG (GPO-trinder 337; Sigma, St Louis, MO, USA) and glycerol by a glycerolkinase-lipase method (Boehringer, Mannheim, Germany) using a semi-automated centrifugal spectrophotometer (Cobas Fara, Roche Diagnostics, Basel, Switzerland). Plasma concentrations of active ghrelin were measured by RIA (Linco Research, Inc.). Plasma active ghrelin concentrations were measured in acidified plasma with $50 \mu \mathrm{l}$ of $1 \mathrm{M}$ $\mathrm{HCl}$ and addition of $10 \mu \mathrm{l}$ of phenylmethylsulfonyl fluoride per $1 \mathrm{ml}$ plasma. Sensitivity of the RIA assay was $7.8 \mathrm{pg} / \mathrm{ml}$ and the difference between duplicate results of a sample was $<10 \% \mathrm{CV}$. The specificity for human ghrelin was $100 \%$. Plasma active glucagon-like peptide 1 (GLP-1) samples were analysed using ELISA (EGLP-35K; Linco Research, Inc.). Plasma active GLP-1 concentrations were measured in plasma after the addition of $10 \mu \mathrm{l}$ dipeptidyl peptidase-4 (DPP-IV) inhibitor per ml blood. Sensitivity of the ELISA assay was $2 \mathrm{pM}$, and the difference between duplicate results of a sample was $<10 \% \mathrm{CV}$. The specificity for active GLP-1 was $100 \%$. Plasma leptin concentrations were measured using the human leptin RIA kit (Linco Research, Inc.). Sensitivity of the leptin RIA assay was $0.05 \mathrm{ng} / \mathrm{ml}$ and the difference between duplicate results of a sample was $<10 \% \mathrm{CV}$. The specificity for human leptin was $100 \%$.

\section{Appetite profile}

Appetite profile was measured using anchored $100 \mathrm{~mm}$ visual analogue scales (VAS). During each respiration chamber session these questionnaires were completed before and after every meal on feelings of hunger, fullness, appetite, satiety, thirst, prospective food consumption and desire to eat. 
The scale was anchored from 'not at all' on the left to 'extremely' on the right. During each respiration chamber session these questionnaires were completed before (07.50 hours) and after (08.20 hours) breakfast, at 10.45 hours, before (12.00 hours) and after (12.20 hours) lunch, at 13.15 hours, at 14.15 hours, before (16.30 hours) and after (17.00 hours) dinner and on the next morning (08.00 hours).

\section{Body composition}

Body composition was determined by underwater weighing in the fasted state. Body mass in air and underwater was determined on a digital balance, accurate to $0.01 \mathrm{~kg}$ (Sauter type E1200). Lung volume was measured simultaneously with the He-dilution technique using a spirometer (Volugraph 2000; Mijnhardt, The Netherlands). Body density was used to calculate body fat according to the two-compartment model with the equation of $\mathrm{Siri}^{(24)}$.

\section{Indirect calorimetry}

$\mathrm{O}_{2}$ consumption and $\mathrm{CO}_{2}$ production were measured in the respiration chamber ${ }^{(25)}$. The respiration chamber is a $14 \mathrm{~m}^{3}$ room furnished with a bed, chair, computer, television, radio cassette player, telephone, intercom, sink and toilet. The room was ventilated with fresh air at a rate of 70-80 litres/ min. The ventilation rate was measured with a dry gas meter (type 4; Schlumberger, Dordrecht, The Netherlands). The concentrations of $\mathrm{O}_{2}$ and $\mathrm{CO}_{2}$ were measured with the use of an IR $\mathrm{CO}_{2}$ analyser (Uras 3G; Hartmann and Braun, Frankfurt, Germany) and two paramagnetic $\mathrm{O}_{2}$ analysers: Magnos 6G (Hartmann and Braun) and type OA184A (Servomex, Crowborough, East Sussex, UK). During each $15 \mathrm{~min}$ period, six samples of outgoing air for each chamber, one sample of fresh air, zero gas and calibration gas were measured. The gas samples to be measured were selected by a computer that also stored and processed the data ${ }^{(25)}$.

\section{Energy expenditure and substrate oxidation}

The $24 \mathrm{~h}$ energy expenditure consists of SMR, diet-induced thermogenesis (DIT) and activity-induced energy expenditure; $24 \mathrm{~h}$ energy expenditure and $24 \mathrm{~h}$ respiratory quotient were measured from 08.00 hours on day 4 to 08.00 hours on day 5. Activity was monitored with a radar system based on the Doppler principle. SMR was defined as the lowest mean energy expenditure measured over three consecutive hours between 00.00 and 07.00 hours. DIT was calculated by plotting energy expenditure against radar output; both were averaged over $30 \mathrm{~min}$ periods. The intercept of the regression line at the lowest radar output represents the energy expenditure in the inactive state (RMR), which consists of SMR and DIT ${ }^{(26)}$. DIT was determined by subtracting SMR from RMR. Activity-induced energy expenditure was determined by subtracting SMR and DIT from $24 \mathrm{~h}$ energy expenditure. Carbohydrate, fat and protein oxidation were calculated from the measurements of $\mathrm{O}_{2}$ consumption, $\mathrm{CO}_{2}$ production, and urinary $\mathrm{N}$ excretion by using the formula of Brouwer ${ }^{(27)}$. Urine samples $(24 \mathrm{~h})$ were collected from the second void on day 4 until the first void on day 5. Samples were collected in containers with $10 \mathrm{ml} \mathrm{H}_{2} \mathrm{SO}_{4}$ to prevent $\mathrm{N}$ loss through evaporation. Volume and $\mathrm{N}$ concentration were measured, the latter with an $\mathrm{N}$ analyser (CHN-O-Rapid; Heraeus, Hanau, Germany).

\section{Dietary fat oxidation}

Labelled fatty acids were obtained from Cambridge Isotope Laboratories (Andover, MA, USA). ${ }^{2} \mathrm{H}$-labelled palmitic acid, d31-palmitic acid (catalogue no. DLM-215), was 98 atom\%. ${ }^{2} \mathrm{H}$-labelled palmitic acid $(20 \mathrm{mg} / \mathrm{kg}$ body weight) was added to chocolate milk, which was heated up to $65^{\circ} \mathrm{C}$ and consumed by the subjects at breakfast. After the ingestion of the chocolate milk with ${ }^{2} \mathrm{H}$-labelled palmitic acid, the cup, in which the chocolate milk was served, was filled with a new portion of chocolate milk to 'rinse' the cup. This second portion of chocolate milk was also heated up to $65^{\circ} \mathrm{C}$ and ingested by the subjects to minimise the loss of ${ }^{2} \mathrm{H}$-labelled palmitic acid. Urine was collected every $2 \mathrm{~h}$ after breakfast up to 20.00 hours. Recovery of the stable isotopes was calculated at $2,4,6,8,10,12$ and $24 \mathrm{~h}$ post-dose according to the method described by Votruba et al. ${ }^{(28)}$. Cumulative recovery of ${ }^{2} \mathrm{H}$ from labelled palmitic acid (\%) over $24 \mathrm{~h}$ in the urine was used as a measure of dietary fat oxidation.

\section{Statistical analysis}

Data are presented as mean values and standard deviations, unless otherwise indicated. The profiles of the plasma concentrations of the measured parameters have patterns and peaks that reflect the absorption of nutrients in the intestine. The aim of the present study was to assess whether the peak of a specific parameter on a relevant point in time differed significantly from baseline, and whether these peaks differ significantly between treatments. A three-factor repeated-measures ANOVA or analysis of covariance (ANCOVA), with value of parameter at $\mathrm{t}=0$ as covariate, was carried out to determine possible differences between the conditions. Post hoc comparisons were made with the Fisher protected least significant difference (PLSD) test. Significance was defined as $P<0.05$. All of the statistical analyses were executed with Statview SE Graphics ${ }^{\mathrm{TM}}$ software (version 4.5; Abacus Concepts Inc., Berkeley, CA, USA).

\section{Results}

The results on $24 \mathrm{~h}$ energy expenditure are shown in Table 1. There were no differences between the conditions in total energy expenditure, $24 \mathrm{~h}$ DIT, SMR, activity-induced energy expenditure and $24 \mathrm{~h}$ non-protein respiratory quotient. In all conditions the subjects were in energy balance (energy intake minus energy expenditure was: water 0.83 (SD 0.8 ) $\mathrm{MJ} / \mathrm{d}$; MSF 0.74 (SD 0.8) MJ/d; lunch eaten 0.73 (SD 0.7) $\mathrm{MJ} / \mathrm{d}$; NS). The continuous measurement of energy expenditure from the moment the subjects entered the respiration chamber until the test lunch revealed no differences between the three conditions. The subjects were thus in a similar metabolic state before lunch. During the $60 \mathrm{~min}$ before the lunch, energy expenditure was equal in all conditions (Fig. 1). However, energy expenditure during the first hour after the eaten and MSF lunch was significantly higher compared with after water (water 6.3 (SD 0.8) $\mathrm{kJ} / \mathrm{min}$; MSF 6.9 (SD 1.0) $\mathrm{kJ} / \mathrm{min}$; 
Table 1. Total energy expenditure, components of energy expenditure and non-protein respiratory quotient $(\mathrm{RQ})$ during the three conditions (Mean values and standard deviations)

\begin{tabular}{|c|c|c|c|c|c|c|}
\hline & \multicolumn{2}{|c|}{ Water } & \multicolumn{2}{|c|}{ MSF } & \multicolumn{2}{|c|}{ Lunch eaten } \\
\hline & Mean & SD & Mean & SD & Mean & SD \\
\hline $\begin{array}{l}24 \mathrm{~h} \text { Non-protein } \\
\mathrm{RQ}\end{array}$ & 0.92 & 0.05 & 0.92 & 0.04 & 0.89 & 0.05 \\
\hline TEE (MJ/d) & 8.44 & 1.03 & 8.53 & 0.88 & 8.45 & 0.67 \\
\hline DIT $(\mathrm{MJ} / \mathrm{d})$ & 0.83 & 0.27 & 0.82 & 0.20 & 0.90 & 0.28 \\
\hline $\begin{array}{l}\text { DIT (\% energy } \\
\text { intake) }\end{array}$ & $9 \cdot 01$ & 2.91 & 8.94 & $2 \cdot 38$ & $9 \cdot 78$ & 3.22 \\
\hline SMR (MJ/d) & 6.07 & 0.73 & 6.09 & 0.51 & 6.05 & 0.44 \\
\hline AEE $(M J / d)$ & 1.54 & 0.58 & 1.68 & 0.47 & 1.50 & 0.39 \\
\hline
\end{tabular}

MSF, modified sham feeding; TEE, total energy expenditure over $24 \mathrm{~h}$; DIT, dietinduced thermogenesis; SMR, sleeping metabolic rate; AEE, activity-induced energy expenditure.

lunch eaten 6.8 (SD 0.7) kJ/min; ANOVA, $F$ 0.449; $P<0.04)$. This difference in energy expenditure between conditions was no longer present in the second hour after MSF and eaten lunch. The $24 \mathrm{~h}$ fat oxidation (water 53 (SD 35) g; MSF 50 (SD 25) g; lunch eaten 65 (SD 29) g) and 24h carbohydrate oxidation (water 293 (SD 73) g; MSF 289 (SD 73) g; lunch eaten 252 (SD 60) g) were not significantly different between conditions.

The percentage ${ }^{2} \mathrm{H}$-labelled palmitic acid recovered over $24 \mathrm{~h}$ was not different between the three conditions (water 22.3 (SD 5.1) \%; MSF 22.4 (SD 5.1) \%; lunch eaten 19.8 (SD 4.6) \%; Fig. 2).

\section{Expectorated meals}

The weights of the MSF meal before and after chewing were compared; this yielded a mean recovery rate of 101.8 (SEM 8.5) \% for total weight and 96.2 (SEM 3.1) \% for dehydrated weight.

\section{Blood samples}

Glucose. Changes in plasma glucose concentrations in response to the lunch condition are presented in Table 2 . At $15 \mathrm{~min}$ after the lunch absolute plasma glucose concentrations were significantly higher after eating than after the MSF and water condition (water 5.1 (SD 0.4) $\mathrm{mmol} / \mathrm{l}$; MSF $5 \cdot 1 \quad(\mathrm{SD} 0 \cdot 3) \mathrm{mmol} / \mathrm{l}$; lunch eaten $5.5 \quad(\mathrm{SD} \quad 0.3) \mathrm{mmol} / \mathrm{l}$; ANCOVA, $F$ 0.071; $P<0 \cdot 0001$; Table 2).

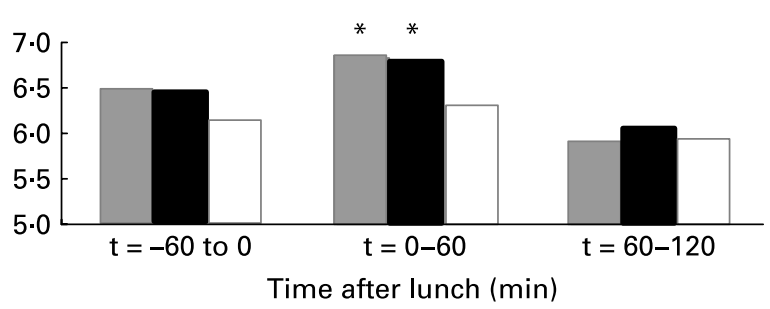

Fig. 1. Mean energy expenditure during $1 \mathrm{~h}$ before the lunch ( -60 to $0 \mathrm{~min}$ ), the first hour after the lunch $(0-60 \mathrm{~min})$ and during the second hour after the lunch (60-120 min) in sham-fed subjects $(\square)$, subjects that ate the lunch $(\square)$ and in subjects given a water lunch $(\square)$. * Mean value was significantly different from that after water (repeated-measures ANOVA; $P<0.05$ ).

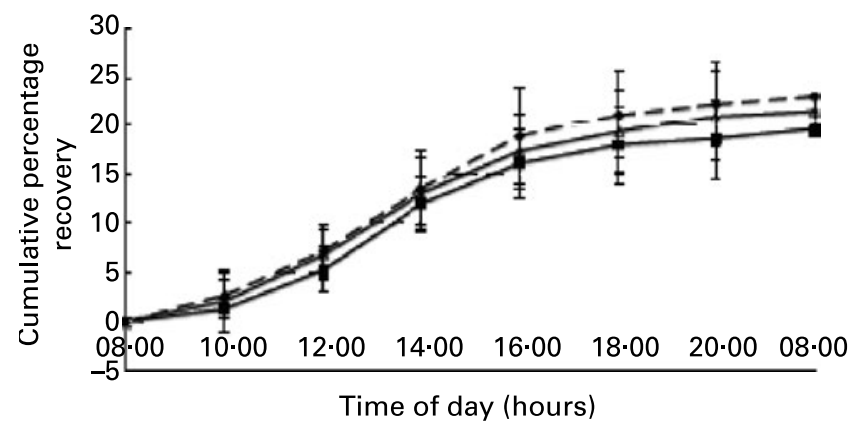

Fig. 2. Mean cumulative percentage recovery of ${ }^{2} \mathrm{H}$ from ${ }^{2} \mathrm{H}$-labelled palmitic acid given at breakfast $(08.00$ hours) in sham-fed subjects (-0-), subjects that ate the lunch $(-\mathbf{-}-)$ and in subjects given a water lunch $(--\triangle--)$. Values are means, with standard deviations represented by vertical bars.

Insulin. Changes in plasma insulin concentrations in response to the lunch condition are presented in Table 2. Absolute plasma insulin concentrations were significantly different between the three conditions $15 \mathrm{~min}$ after the lunch, with the highest plasma insulin concentrations in the eating condition and the lowest plasma insulin concentrations in the water condition (ANCOVA, $F$ 15.514; $P<0.0001$; Table 2). The increase in plasma insulin concentrations $15 \mathrm{~min}$ after the lunch was significantly higher in the eating condition compared with the MSF and water conditions (ANOVA, $F$ 2.402; $P<0.0001$; Table 2). At $120 \mathrm{~min}$ after the lunch absolute plasma insulin concentrations were significantly higher in the eating condition compared with the MSF and water conditions (ANCOVA, $F$ 9.700; $P<0.02$; Table 2).

Non-esterified fatty acids. Changes in plasma NEFA concentrations in response to the lunch condition are presented in Fig. 3. At 15 and $60 \mathrm{~min}$ after the lunch absolute plasma NEFA concentrations were significantly higher after MSF and the water condition compared with after the eaten condition (ANCOVA, $\mathrm{t}=15, F 5.473, P<0.0001 ; \mathrm{t}=60$, $F$ 5.054, $P<0.0001$; data not shown). The change in NEFA plasma concentrations $15 \mathrm{~min}$ after the lunch was significantly different between the three conditions, with an increase in NEFA plasma concentrations in the MSF and the water conditions and a decrease in NEFA plasma concentrations in the eating condition (ANOVA, $F$ 63.132; $P<0.0001$; Fig. 3). At $60 \mathrm{~min}$ after the lunch the changes in NEFA plasma concentrations were still significantly different after MSF and the water condition compared with after the eaten condition (ANOVA, $F$ 81.598; $P<0.0001$; Fig. 3). At $2 \mathrm{~h}$ after the lunch, differences in NEFA plasma concentrations between the conditions were no longer observed.

Triacylglycerol and glycerol. Changes in plasma TAG concentrations in response to the lunch condition are presented in Fig. 4. Absolute plasma TAG concentrations were significantly different between the three conditions $15 \mathrm{~min}$ after the lunch, with the highest plasma TAG concentrations in the water condition and the lowest plasma TAG concentrations in the MSF condition (ANCOVA, $F$ 2.984; $P<0.03$; data not shown). At $60 \mathrm{~min}$ after the lunch absolute plasma TAG concentrations were significantly lower after MSF and the water condition compared with after the eaten condition (ANCOVA, $F$ 1.729; $P<0.02$; data not shown). At $120 \mathrm{~min}$ after the lunch absolute plasma TAG concentrations were no 
Table 2. Baseline and changes in plasma concentrations of glucose, insulin, glucagon-like peptide 1 (GLP-1) and leptin (Mean values and standard deviations)

\begin{tabular}{|c|c|c|c|c|c|c|c|c|c|c|c|c|c|c|c|c|c|c|}
\hline \multirow[b]{2}{*}{ Blood parameters } & \multicolumn{2}{|c|}{$t=0$} & \multicolumn{2}{|c|}{$\mathrm{t}=15 \min$} & \multicolumn{2}{|c|}{$\Delta 15 \min$} & \multicolumn{2}{|c|}{$\mathrm{t}=30 \min$} & \multicolumn{2}{|c|}{$\Delta 30 \min$} & \multicolumn{2}{|c|}{$\mathrm{t}=60 \min$} & \multicolumn{2}{|c|}{$\Delta 60 \min$} & \multicolumn{2}{|c|}{$\mathrm{t}=120 \min$} & \multicolumn{2}{|c|}{$\Delta 120 \min$} \\
\hline & Mean & SD & Mean & SD & Mean & SD & Mean & SD & Mean & SD & Mean & SD & Mean & SD & Mean & SD & Mean & SD \\
\hline \multicolumn{19}{|l|}{ Glucose (mmol/l) } \\
\hline $\begin{array}{l}\text { After modified } \\
\text { sham feeding }\end{array}$ & $5 \cdot 0$ & 0.4 & $5 \cdot 1^{*}$ & 0.3 & 0.1 & 0.3 & - & & - & & 5.0 & 0.4 & 0.0 & 0.2 & 4.9 & 0.2 & -0.1 & 0.3 \\
\hline After water & $5 \cdot 1$ & 0.3 & $5 \cdot 1^{*}$ & 0.4 & 0.0 & 0.4 & - & & - & & 4.9 & 0.3 & -0.1 & 0.3 & 4.9 & 0.3 & -0.2 & 0.3 \\
\hline After eating & $5 \cdot 1$ & 0.3 & 5.5 & 0.3 & 0.4 & 0.2 & - & & - & & 4.9 & 0.2 & -0.1 & 0.3 & 4.9 & 0.1 & -0.1 & 0.3 \\
\hline \multicolumn{19}{|l|}{ Insulin (units/l) } \\
\hline $\begin{array}{l}\text { After modified } \\
\text { sham feeding }\end{array}$ & $12 \cdot 3$ & $3 \cdot 2$ & $13 \cdot 2^{*}$ & $4 \cdot 0$ & $0.9^{\mathrm{a}}$ & $3 \cdot 2$ & - & & - & & $10 \cdot 0$ & $2 \cdot 6$ & $-2 \cdot 3$ & $2 \cdot 9$ & $10 \cdot 0^{*}$ & $2 \cdot 0$ & $-2 \cdot 3$ & 3.4 \\
\hline After water & $12 \cdot 1$ & 3.8 & $10 \cdot 0^{*} \dagger$ & 3.4 & $-2 \cdot 1^{a}$ & $3 \cdot 2$ & - & & - & & $10 \cdot 1$ & 3.4 & $-2 \cdot 0$ & $3 \cdot 3$ & $9 \cdot 2^{*}$ & $2 \cdot 3$ & $-2 \cdot 8$ & $3 \cdot 0$ \\
\hline After eating & 11.3 & 3.1 & 22.3 & 3.3 & $11 \cdot 1^{\mathrm{b}}$ & 3.6 & - & & - & & 11.9 & 3.7 & 0.7 & $3 \cdot 1$ & 11.9 & $2 \cdot 5$ & 0.6 & $2 \cdot 8$ \\
\hline \multicolumn{19}{|l|}{ GLP-1 (pmol/l) } \\
\hline $\begin{array}{l}\text { After modified } \\
\text { sham feeding }\end{array}$ & $9 \cdot 2^{a}$ & 4.5 & $10 \cdot 2$ & $4 \cdot 4$ & $0.6^{a}$ & $2 \cdot 0$ & $8 \cdot 3$ & $4 \cdot 1$ & $-0 \cdot 7^{\mathrm{a}}$ & 1.5 & 8.9 & $5 \cdot 0$ & $0 \cdot 3^{\mathrm{a}}$ & 1.9 & 8.9 & $6 \cdot 8$ & $-0.1^{a}$ & $3 \cdot 0$ \\
\hline After water & 7.9 & $5 \cdot 6$ & $7 \cdot 2 \dagger$ & $4 \cdot 3$ & $-0.3^{a}$ & $1 \cdot 7$ & $7 \cdot 2^{*}$ & $4 \cdot 7$ & $-0.6^{a}$ & 1.5 & 8.8 & $4 \cdot 4$ & $-0.6^{a}$ & $1 \cdot 2$ & $8 \cdot 6^{*}$ & $5 \cdot 1$ & $-0.4^{a}$ & $1 \cdot 7$ \\
\hline After eating & $7 \cdot 2^{\mathrm{b}}$ & 4.4 & 8.9 & $4 \cdot 4$ & $2 \cdot 2^{\mathrm{b}}$ & $2 \cdot 3$ & 9.8 & $5 \cdot 8$ & $3 \cdot 4^{\mathrm{b}}$ & $2 \cdot 0$ & 11.5 & $7 \cdot 4$ & $5 \cdot 8^{\mathrm{b}}$ & 3.8 & $11 \cdot 0$ & $5 \cdot 7$ & $3 \cdot 8^{\mathrm{b}}$ & $2 \cdot 1$ \\
\hline \multicolumn{19}{|l|}{ Leptin (ng/ml) } \\
\hline $\begin{array}{l}\text { After modified } \\
\text { sham feeding }\end{array}$ & $14 \cdot 0$ & $10 \cdot 1$ & - & & - & & $15 \cdot 1$ & 9.9 & $1 \cdot 1$ & $2 \cdot 2$ & - & & - & & $15 \cdot 2$ & $9 \cdot 1$ & 1.3 & $3 \cdot 2$ \\
\hline After water & 14.9 & 11.0 & - & & - & & $14 \cdot 3$ & $10 \cdot 3$ & -0.6 & 3.4 & - & & - & & $15 \cdot 1$ & 11.3 & 0.2 & $2 \cdot 1$ \\
\hline After eating & $13 \cdot 2$ & 8.8 & - & & - & & 14.4 & 8.6 & $1 \cdot 2$ & $2 \cdot 8$ & - & & - & & $14 \cdot 6$ & $9 \cdot 3$ & 1.4 & 3.5 \\
\hline
\end{tabular}

${ }^{a, b}$ Mean values for a parameter within a column with unlike superscript letters were significantly different (repeated-measures ANOVA; $P<0.05$ ).

*Mean value was significantly different from that after eating (ANCOVA; $P<0.05$ ).

† Mean value was significantly different from that after modified sham feeding (ANCOVA; $P<0.05$ ). 


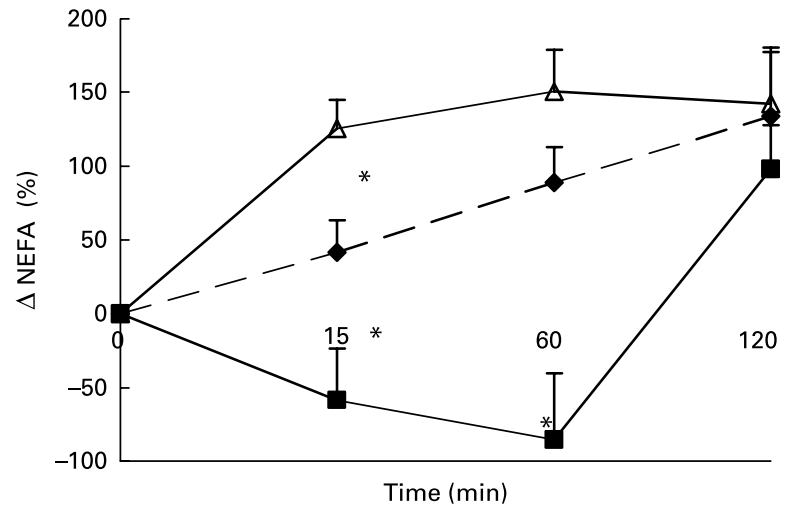

Fig. 3. Percentage change in plasma NEFA concentrations in sham-fed subjects (- --$)$, subjects that ate the lunch $(-\mathbf{\square}-)$ and in subjects given a water lunch $(-\Delta-)$. Values are means, with standard errors represented by vertical bars. ${ }^{*}$ Mean value was significantly different from that after water (repeatedmeasures ANOVA; $P<0.05)$.

longer significantly different between the MSF and eating conditions (ANCOVA, data not shown). MSF and eating provoked a significantly lower decrease in TAG concentrations compared with the water condition, calculated as area-under-the-curve $\Delta(F$ 19851.451; $P<0.0002)$ and $60 \mathrm{~min}(F \mathrm{191} .405 ; P<0.0001)$ and $120 \mathrm{~min}(F$ 189.638; $P<0.0001)$ after the lunch conditions (ANOVA; Fig. 4).

Changes in plasma glycerol concentrations in response to the lunch condition are presented in Fig. 5. Absolute plasma glycerol concentrations were significantly higher $15 \mathrm{~min}$ ( $F \quad 1.242 ; P<0.008$ ) after the water lunch and $60 \mathrm{~min}$ $(F 0.534 ; P<0.03)$ after the water and MSF lunches compared with after the eaten lunch (ANCOVA; data not shown). The increase in plasma glycerol concentrations $15 \mathrm{~min}$ after the water lunch was significantly different from the decrease in plasma glycerol concentrations $15 \mathrm{~min}$ after the MSF and eaten lunches (ANOVA, F 20.903; P<0.007; Fig. 5).

Glucagon-like peptide 1. Changes in plasma GLP-1 concentrations in response to the lunch condition are presented in Table 2. Absolute plasma GLP-1 concentrations were significantly lower $15 \mathrm{~min}$ after the water lunch compared with

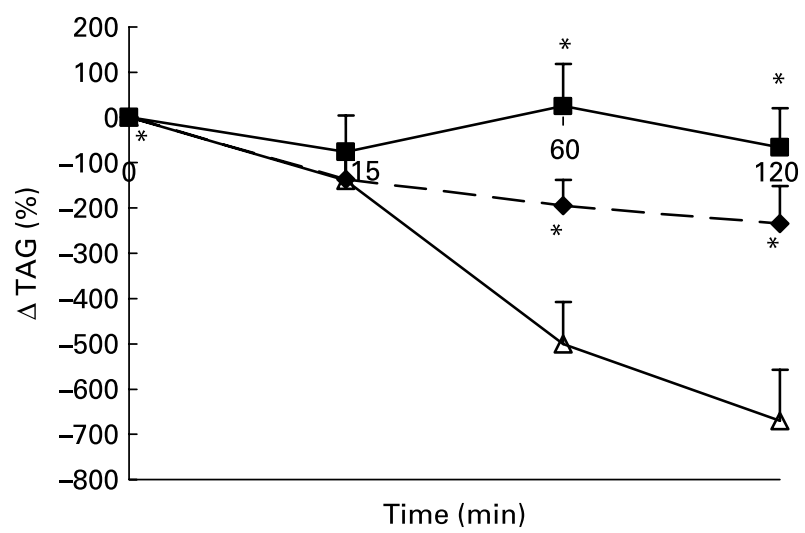

Fig. 4. Percentage of change in plasma TAG concentrations in sham-fed subjects (-- - ), subjects that ate the lunch (-ם-) and in subjects given a water lunch $(-\triangle-)$. Values are means, with standard errors represented by vertical bars. * Mean value was significantly different from that after water (repeated-measures ANOVA; $P<0.05$ ).

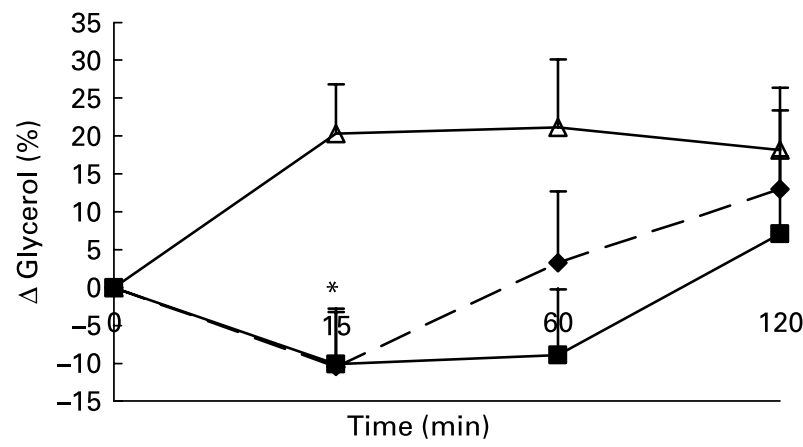

Fig. 5. Percentage of change in plasma glycerol concentrations in sham-fed subjects $(---)$, subjects that ate the lunch $(-\mathbf{-}-)$ and in subjects given a water lunch $(-\Delta-)$. Values are means, with standard errors represented by vertical bars. *Mean value was significantly different from that after water (repeated-measures ANOVA; $P<0.05$ ).

after the MSF lunch. However, this was completely explained by significant differences in plasma GLP-1 concentrations at $\mathrm{t}=0$ (ANCOVA, $F$ 78.211; $P<0.0001$; Table 2). At 30 and 120 min after the water lunch, absolute plasma GLP-1 concentrations were significantly lower compared with after the eaten lunch (ANCOVA, t = 30: $F 1 \cdot 104, P<0 \cdot 02 ; \mathrm{t}=120: F 2 \cdot 890$, $P<0.04$; Table 2). The increase in plasma GLP-1 concentrations in the eating condition was significantly different from the MSF and water conditions at each time point after lunch (ANOVA, $\mathrm{t}=15: F$ 1.59; $P<0.01, \mathrm{t}=30: F$ 1.328; $P<0.0001, \mathrm{t}=60: F$ 1.91; $P<0.0001, \mathrm{t}=120: F$ 1.699: $P<0 \cdot 0001$; Table 2).

Ghrelin. Changes in plasma total active ghrelin concentrations in response to the lunch condition are presented in Fig. 6. Absolute plasma total active ghrelin concentrations were significantly higher $30 \mathrm{~min}$ after the water lunch compared with after the eaten lunch (ANCOVA, $F$ 2.826; $P<0.05$; data not shown). The decrease in plasma total active ghrelin concentrations $30 \mathrm{~min}$ after the MSF and eaten lunches was significantly different from the increase in plasma total active ghrelin concentrations $30 \mathrm{~min}$ after the water lunch (ANOVA, $F$ 29.469; $P<0 \cdot 04$; Fig. 6).

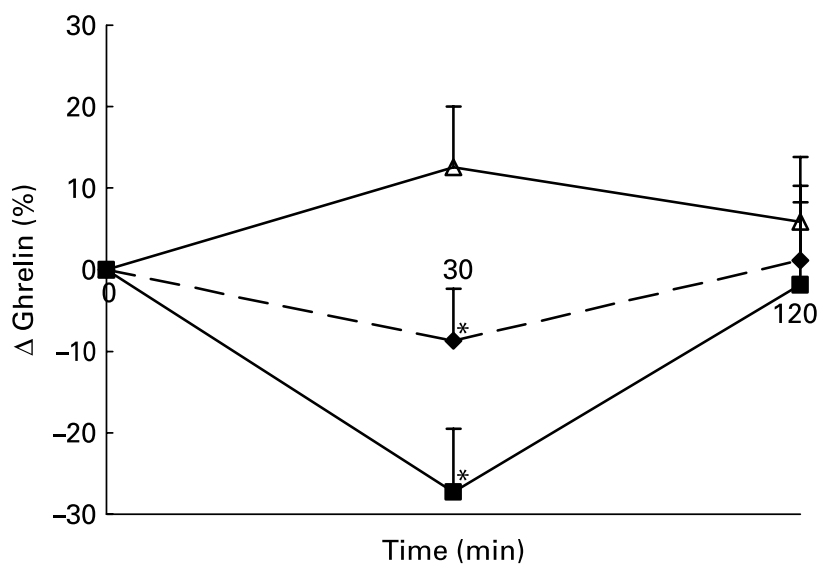

Fig. 6. Percentage of change in plasma active ghrelin concentrations in sham-fed subjects $(---)$, subjects that ate the lunch $(-\mathbf{\square}-)$ and in subjects given a water lunch $(-\triangle-)$. Values are means, with standard errors represented by vertical bars. * Mean value was significantly different from that after water (repeated-measures ANOVA; $P<0.05$ ). 
Leptin. Changes in plasma total active leptin concentrations in response to the lunch condition are presented in Table 2. Eating, MSF and water ingestion had no effects on plasma leptin concentrations.

\section{Appetite profile}

Changes in VAS scores for satiety in response to the lunch condition are presented in Fig. 7. The increase in VAS scores for satiety in the eating condition was significantly different from the MSF and water conditions $85 \mathrm{~min}$ ( $F$ 15.91; $P<0.004)$ and $250 \mathrm{~min}(F 11.821 ; P<0.02)$ after lunch (ANOVA; Fig. 7). The area under the curve of VAS scores for satiety (area-under-the-curve water 425 (SD 144) mm VAS $\times$ h; MSF $402(\mathrm{SD} 110) \mathrm{mm}$ VAS $\times$ h; lunch eaten 500 (SD 147) mm VAS $\times$ h) were significantly different between the MSF condition or water condition, and the eating condition, but not between the water and MSF condition (ANOVA, F 3120.822; P<0.0003; Fig. 7).

\section{Discussion}

In the present study, oral fat stimulation by MSF increased energy expenditure, plasma NEFA concentrations, and attenuated the decrease in plasma TAG and the increase in glycerol and active ghrelin concentrations up to $1 \mathrm{~h}$ after the MSF meal. Over a longer period of time, i.e. $24 \mathrm{~h}$, oral fat stimulation had no effects on substrate oxidation, DIT or total energy expenditure. We kept circumstances before the test lunch as equal as possible.

Previously, we have observed increased sensory-specific satiety as well as increases in metabolite concentrations in the blood following oral fat stimulation by $\mathrm{MSF}^{(4,29)}$. Here, we add an increase in post-MSF thermogenesis, for $1 \mathrm{~h}$, to this. However, in the present study, the increase in satiety following MSF failed to reach significance.

The observed effects of oral fat stimulation by MSF and eating, a few hours after a high-fat breakfast, on plasma metabolites (NEFA, TAG and glycerol) has been named a 'second-meal effect'. This 'second-meal effect' has been observed in previous experiments ${ }^{(5-7,9,12-15,30)}$, which have led to a 'storage theory'. The appearance after a second meal of chylomicrons, containing fat from the first meal, has

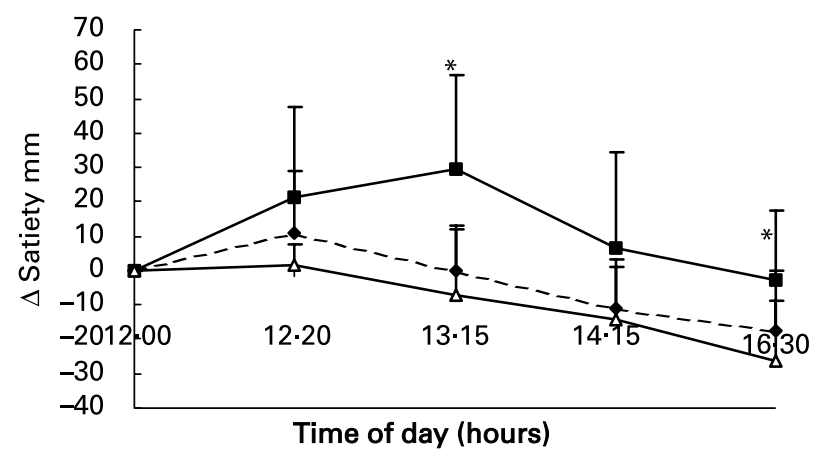

Fig. 7. Change in satiety scores on a visual analogue scale $(\mathrm{mm})$ over $4.5 \mathrm{~h}$ after the lunch in sham-fed subjects $(---)$, subjects that ate the lunch $(-\square-)$ and in subjects given a water lunch $(-\triangle-)$. Values are means, with standard errors represented by vertical bars. ${ }^{*}$ Mean value was significantly different from that after water (repeated-measures ANOVA; $P<0.05$ ). led to the idea that a proportion of fat from the first meal remains in the gut lumen or in the enterocyte and enters the plasma pool after ingesting a second meal ${ }^{(31-34)}$. In the present study, MSF attenuated the decrease in TAG, which was observed 60 and $120 \mathrm{~min}$ after water ingestion. This observation may be due to oral stimulation with fat as we showed previously ${ }^{(4)}$. Plasma TAG were most probably elevated after breakfast and were still declining when the lunch was given. Moreover, the lunch was smaller (provided $20 \%$ of each subject's specific daily energy requirements) in comparison with the breakfast (provided $30 \%$ of each subject's specific daily energy requirements), which may have been of importance for the observed small increase in plasma TAG after the eaten lunch.

In line with this 'storage theory', we hypothesised that ${ }^{2} \mathrm{H}$-labelled palmitic acid added to a high-fat breakfast will reappear in the circulation and will subsequently be oxidised after a second, MSF or eaten, high-fat meal. The recovery of the ${ }^{2} \mathrm{H}$ from the ${ }^{2} \mathrm{H}$-labelled palmitic acid in the present study was relatively high in comparison with the recovery found in two studies that have used a similar protocol ${ }^{(35,36)}$. However, the $24 \mathrm{~h}$ recovery of the ${ }^{2} \mathrm{H}$-labelled palmitic acid in urine was not statistically different between the three conditions. This indicates that oral fat stimulation by MSF or eating did not affect the oxidation of ${ }^{2} \mathrm{H}$-labelled palmitic acid from the breakfast after possible reappearance.

Furthermore, the plasma fatty acid profile did not change after MSF (data not shown), which suggests that the observed increase in plasma NEFA was due to the release of NEFA from a mixed pool rather than from the previous meal (breakfast). The latter observation is supported by the similar $24 \mathrm{~h}$ recovery of the ${ }^{2} \mathrm{H}$-labelled palmitic acid added to the breakfast in the three conditions.

We observed a short effect of oral fat stimulation by MSF on plasma GLP-1 concentrations. After oral nutrient ingestion, GLP-1 is released into the circulation in a biphasic pattern ${ }^{(37)}$. The early phase of GLP-1 secretion (after 10-15 min) has been suggested to be mediated by the autonomic nervous system rather than by direct nutrient contact with the L-cells ${ }^{(38,39)}$. However, the higher plasma GLP-1 concentrations $15 \mathrm{~min}$ after the MSF lunch are most probably due to the significantly higher plasma GLP-1 concentrations before the MSF lunch compared with the two other lunches.

In the present study, oral fat stimulation by MSF suppressed active plasma ghrelin concentrations. This is in line with the observed significant suppression of plasma ghrelin when a meal was preceded by MSF by Heath et al. ${ }^{(40)}$.

Plasma leptin concentrations were not affected by eating or oral stimulation by MSF of fat over the course of $2 \mathrm{~h}$.

The effects observed following MSF are unlikely to be produced by the ingestion of food, as shown by the high total recovery of the weights of the expectorated meals. Earlier oral stimulation studies have shown that the amount of food which is accidentally swallowed during MSF is no more than a few grams ${ }^{(5,7-9,13,15,16,40)}$.

The increase in MSF-induced energy expenditure similar to DIT of eating for $1 \mathrm{~h}$ shows the duration of the cephalic response. Until now the cephalic response has been observed as a pre-absorptive insulin response ${ }^{(41,42)}$, by comparing eating the same foods yet hedonically different ${ }^{(43)}$, or by consumption of unfamiliar food. Here we show that oral exposure 
to food, without ingestion of nutrients, induces anticipatory responses to food that result in increased energy expenditure comparable with the DIT of the same food being eaten, for $1 \mathrm{~h}$.

Together with the observations of the re-appearance of metabolites, and the previous observations on satiety, from our and other studies, we conclude that the metabolic effects of oral exposure to fat are multi-factorial and last at least up to $1 \mathrm{~h}$. Studies in which oral exposure to fat was combined with a (gastric) fat load and/or given in the fasted state have observed effects on TAG concentrations for a longer period of time, which suggests that differences in, for instance, the metabolic state of the subjects or the fat-containing oral stimulus may influence physiological responses ${ }^{(6-9,16)}$.

These findings indicate that metabolism is triggered during eating even before nutrients are absorbed. This triggering mechanism may serve as a feed-forward system to optimise the absorption and utilisation of nutrients ${ }^{(44)}$. The physiological anticipatory responses to food due to mere sensory exposure may be interpreted as being advantageous and disadvantageous. If the available metabolites (after re-appearance in blood plasma) will be oxidised, then a greater amount of dietary fat will be oxidised and not stored in fat tissue. Recently, a difference in trafficking of dietary fat was shown in obesityprone and obesity-resistant rats ${ }^{(45)}$. The obesity-resistant phenotype was associated with greater oxidation and less storage of dietary fat than was the obesity-prone phenotype. In a recent human study, dietary fat oxidation was negatively related to percentage body fat, and lean subjects had the highest and obese subjects the lowest values ${ }^{(36)}$. Thus, increasing the availability of oxidisable metabolites in blood plasma due to mere sensory exposure may be beneficial for dietary fat oxidation. However, this effect on dietary fat oxidation may be rather small, because we observed no effect of mere sensory exposure on dietary fat oxidation over a period of $2-24 \mathrm{~h}$. Raised TAG and NEFA in the postprandial state contribute to the obesity-associated pathologies such as type 2 diabetes, atherosclerosis and hypertension. It is therefore of importance to clarify the mechanisms behind the metabolic effects observed after the consumption of high-fat foods, and whether these are influenced by the oral exposure to fats and the preceding meal. Summarising, mere sensory exposure to meals rich in specific fatty acids has effects on physiological and metabolic variables that resemble the effects observed after eating, which last up to $1 \mathrm{~h}$. Just oral signals from fat, without contributing to energy intake, contribute to metabolic satiety for up to $1 \mathrm{~h}$. Effects of oral fat perception by MSF contributed to energy expenditure, lowered plasma active ghrelin concentrations and mimicked the effects on metabolites observed after eating in the postprandial state for up to $1 \mathrm{~h}$.

\section{Acknowledgements}

The study was sponsored by Top Institute Food and Nutrition, Wageningen, The Netherlands and by the European project DiOGenes (contract no. FP6-513946).

We thank Maartje Spetter, Krista Morren, Loek Wouters and Paul Schoffelen for their contributions to the study. A. J. S. designed the experiment, collected the data, analysed the data and wrote the manuscript. M. P. L. collected data and helped write the manuscript, M. S. W.-P. designed the experiment, helped analyse the data and write the manuscript, and supervised the project. None of the authors had any financial or personal interest in any company or organisation sponsoring the research.

\section{References}

1. National Heart Lung and Blood Institute (1998) Clinical Guidelines on the Identification, Evaluation, and Treatment of Overweight and Obesity in Adults: The Evidence Report. Bethesda, MD: US Department of Health and Human Services, National Institutes of Health. http://www.nhlbi.nih.gov/guidelines/obesity/ ob_gdlns.htm (accessed 10 October 2007).

2. Poothullil JM (2002) Role of oral sensory signals in determining meal size in lean women. Nutrition 18, 479-483.

3. Schilstra AJ (1981) Meal-interval correlations: what can they tell us? Physiol Behav 27, 299-304.

4. Smeets AJ \& Westerterp-Plantenga MS (2006) Satiety and substrate mobilization after oral fat stimulation. Br J Nutr 95, 795-801.

5. Mattes RD (1996) Oral fat exposure alters postprandial lipid metabolism in humans. Am J Clin Nutr 63, 911-917.

6. Mattes RD (2001) The taste of fat elevates postprandial triacylglycerol. Physiol Behav 74, 343-348.

7. Mattes RD (2001) Oral exposure to butter, but not fat replacers elevates postprandial triacylglycerol concentration in humans. J Nutr 131, 1491-1496.

8. Tittelbach TJ \& Mattes RD (2001) Oral stimulation influences postprandial triacylglycerol concentrations in humans: nutrient specificity. J Am Coll Nutr 20, 485-493.

9. Mattes RD (2002) Oral fat exposure increases the first phase triacylglycerol concentration due to release of stored lipid in humans. J Nutr 132, 3656-3662.

10. Tittlebach TJ \& Mattes RD (2002) Effect of orosensory stimulation on postprandial thermogenesis in humans. Physiol Behav 75, 71-81.

11. Coelho SB, de Sales RL, Iyer SS, et al. (2006) Effects of peanut oil load on energy expenditure, body composition, lipid profile, and appetite in lean and overweight adults. Nutrition 22, $585-592$.

12. Robertson MD, Jackson KG, Fielding BA, et al. (1999) Modified sham feeding of a modest-fat meal suppresses plasma non-esterified fatty acids. Proc Nutr Soc 59, 123A.

13. Jackson KG, Robertson MD, Deane LO, et al. (2000) The effect of modified sham-feeding meals of varying fat content on postprandial triacylglycerol, insulin and glucose response. Proc Nutr Soc 59, 14A.

14. Robertson MD, Mason AO \& Frayn KN (2000) Oro-sensory stimulation prior to fat ingestion impairs postprandial fat tolerance. Int J Obes 24, S55.

15. Jackson KG, Robertson MD, Fielding BA, et al. (2001) Second meal effects: modified sham feeding does not provoke the release of stored triacylglycerol from a previous high-fat meal. Br J Nutr 85, 149-156.

16. Robertson MD, Mason AO \& Frayn KN (2002) Timing of vagal stimulation affects postprandial lipid metabolism in humans. Am J Clin Nutr 76, 71-77.

17. LeBlanc J \& Cabanac M (1989) Cephalic postprandial thermogenesis in human subjects. Physiol Behav 46, 479-482.

18. LeBlanc J \& Soucy J (1996) Interactions between postprandial thermogenesis, sensory stimulation of feeding, and hunger. Am J Physiol 271, R936-R940.

19. Brondel L, Fricker J \& Fantino M (1999) Postprandial thermogenesis and alimentary sensory stimulation in human subjects Int J Obes Relat Metab Disord 23, 34-40. 
20. Prat-Larquemin L, Oppert JM, Bellisle F, et al. (2000) Sweet taste of aspartame and sucrose: effects on diet-induced thermogenesis. Appetite 34, 245-251.

21. Stunkard AJ \& Messick S (1985) The three-factor eating questionnaire to measure dietary restraint, disinhibition and hunger. J Psychosom Res 29, 71-83.

22. Harris JA \& Benedict FG (1918) A biometric study of human basal metabolism. Proc Natl Acad Sci U S A 4, 370-373.

23. Westerterp KR (1999) Exercise and Energy Balance. Milan, Italy: Edra, Medical Publishing and New Media.

24. Siri WE (1956) The gross composition of the body. Adv Biol Med Phys 4, 239-280.

25. Schoffelen PF, Westerterp KR, Saris WH, et al. (1997) A dualrespiration chamber system with automated calibration. J Appl Physiol 83, 2064-2072.

26. Westerterp KR, Wilson SA \& Rolland V (1999) Diet induced thermogenesis measured over $24 \mathrm{~h}$ in a respiration chamber: effect of diet composition. Int J Obes Relat Metab Disord 23, 287-292.

27. Brouwer E (1957) On simple formulae for calculating the heat expenditure and the quantities of carbohydrate and fat oxidized in metabolism of men and animals, from gaseous exchange (oxygen intake and carbonic acid output) and urine-N. Acta Physiol Pharmacol Neerl 6, 795-802.

28. Votruba SB, Zeddun SM \& Schoeller DA (2001) Validation of deuterium labeled fatty acids for the measurement of dietary fat oxidation: a method for measuring fat-oxidation in free-living subjects. Int J Obes Relat Metab Disord 25, 1240-1245.

29. Smeets AJ \& Westerterp-Plantenga MS (2006) Oral exposure and sensory-specific satiety. Physiol Behav 89, 281-286.

30. Robertson MD, Jackson KG, Williams CM, et al. (2001) Prolonged effects of modified sham feeding on energy substrate mobilization. Am J Clin Nutr 73, 111-117.

31. Jackson KG, Robertson MD, Fielding BA, et al. (2002) Olive oil increases of triacylglycerol-rich chylomicron particles compared with other oils: an effect retained when a second meal is fed. Am J Clin Nutr 76, 942-949.

32. Peel AS, Zampelas A, Williams CM, et al. (1993) A novel antiserum specific to apolipoprotein B-48: application in the investigation of postprandial lipidaemia in humans. Clin Sci (Lond) $\mathbf{8 5}, 521-524$
33. Fielding BA, Callow J, Owen RM, et al. (1996) Postprandial lipemia: the origin of an early peak studied by specific dietary fatty acid intake during sequential meals. Am J Clin Nutr 63, $36-41$.

34. Evans K, Kuusela PJ, Cruz ML, et al. (1998) Rapid chylomicron appearance following sequential meals: effects of second meal composition. Br J Nutr 79, 425-429.

35. Votruba SB, Zeddun SM \& Shoeller DA (2001) Validation of deuterium labeled fatty acids for the measurement of dietary fat oxidation: a method for measuring fat-oxidation in freeliving subjects. Int J Obes 25, 1240-1245.

36. Westerterp KR, Smeets A, Lejeune MP, et al. (2008) Dietary fat oxidation as a function of body fat. Am J Clin Nutr 87, 132-135.

37. Herrmann C, Goke R, Richter G, et al. (1995) Glucagon-like peptide-1 and glucose-dependent insulin-releasing polypeptide plasma levels in response to nutrients. Digestion 56, 117-126.

38. Balks HJ, Holst JJ, von zur Muhlen A, et al. (1997) Rapid oscillations in plasma glucagon-like peptide-1 (GLP-1) in humans: cholinergic control of GLP-1 secretion via muscarinic receptors. $J$ Clin Endocrinol Metab 82, 786-790.

39. Rocca AS \& Brubaker PL (1999) Role of the vagus nerve in mediating proximal nutrient-induced glucagon-like peptide-1 secretion. Endocrinology 140, 1687-1694.

40. Heath RB, Jones R, Frayn KN, et al. (2004) Vagal stimulation exaggerates the inhibitory ghrelin response to oral fat in humans. J Endocrinol 180, 273-281.

41. Bellisle F, Louis-Sylvestre J, Demozay F, et al. (1985) Cephalic phase of insulin secretion and food stimulation in humans: a new perspective. Am J Physiol 249, E639-E645.

42. Strubbe JH (1992) Parasympathetic involvement in rapid mealassociated conditioned insulin secretion in the rat. Am J Physiol 263, R615-R618.

43. LeBlanc J \& Brondel L (1985) Role of palatability on mealinduced thermogenesis in human subjects. Am J Physiol 248, E333-E336.

44. Powley TL (2000) Vagal circuitry mediating cephalic-phase responses to food. Appetite 34, 184-188.

45. Jackman MR, Kramer RE, Maclean PS, et al. (2006) Trafficking of dietary fat in obesity prone and obesity resistant rats. Am J Physiol Endocrinol Metab 291, E1083-E1091. 